\title{
Serotonin Enhances Central Olfactory Neuron Responses to Female Sex Pheromone in the Male Sphinx Moth Manduca sexta
}

\author{
Peter Kloppenburg,, ${ }^{1,2}$ Donald Ferns, ${ }^{3}$ and Alison R. Mercer ${ }^{2,3}$ \\ 1 Section of Neurobiology and Behavior, Cornell University, Ithaca, New York 14853, ${ }^{2}$ Arizona Research Laboratories, \\ Division of Neurobiology, University of Arizona, Tucson, Arizona 85721, and ${ }^{3}$ Centre for Neuroscience and Department of \\ Zoology, University of Otago, Dunedin, New Zealand
}

In the brain of the sphinx moth Manduca sexta, sex-pheromonal information is processed in a prominent male-specific area of the antennal lobe called the macroglomerular complex (MGC). Whole-cell patch-clamp recordings from identified projection (output) neurons in the MGC have shown that serotonin [5-hydroxytryptamine (5-HT)] increases both the excitability of MGC projection neurons and their responses to stimulation with pheromone. At least two types of voltage-activated potassium currents in these cells are modulated by 5-HT. 5-HT decreases the maximal conductance of a transient potassium current $\left(I_{A}\right)$ and shifts its voltage for half-maximal inactivation to more negative potentials without affecting the half-maximal voltage for activation. This reduces the "window current" between the voltage activation and inactivation curves, decreas- ing the tonically active $I_{A}$ near the resting potential and causing the cell to depolarize. 5-HT's effect in this case is to decrease both the transient and resting $\mathrm{K}^{+}$conductance by modulating the same channel $\left(I_{A}\right)$. 5-HT also decreases the maximal conductance of a sustained potassium current $\left[I_{K(V)}\right]$ without affecting its voltage dependence. Using HPLC, we show also that levels of 5-HT in the antennal lobes fluctuate significantly over a $24 \mathrm{hr}$ period. Interestingly, 5-HT levels are highest at times when the moths are most active. We suggest that by controlling the responsiveness of antennal-lobe projection neurons to olfactory stimuli, 5-HT will have significant impact on the performance of odor-dependent behaviors.

Key words: olfaction; pheromone; neuromodulation; serotonin; $K^{+}$currents; glomeruli
To optimize information gathering, sensory systems have evolved a variety of mechanisms that enable them to adapt to changes in environmental conditions. In vertebrate and invertebrate sensory systems, the monoamine serotonin [5-hydroxytryptamine (5-HT)] has been strongly implicated in such events. For example, 5-HT alters the chemosensitivity of vertebrate taste receptors (see Ewald and Roper, 1994), enhances the responsiveness of mechanosensitive neurons in the marine mollusc Aplysia californica (see Byrne and Kandel, 1996), and has been implicated in switching insect photoreceptors from a high-acuity, low-sensitivity day state to a low-acuity, high-sensitivity night state (see Weckström and Laughlin, 1995).

5-HT has also been detected in primary olfactory centers of the brain of many species, but its contribution to olfactory information processing remains unclear. One experimental system that has served very successfully as a model to understand olfactory information processing is the macroglomerular complex (MGC) of the male sphinx moth Manduca sexta (Hildebrand, 1995, 1996; Hildebrand and Shepherd, 1997). Like other glomeruli in the primary olfactory centers [antennal lobes (ALs)] of the moth, the

\footnotetext{
Received May 17, 1999; revised July 2, 1999; accepted July 12, 1999.

This work was supported by Deutsche Forschungsgemeinschaft Grant K1 762/1-1 to P.K., University of Otago Grant MFZ B22 to A.R.M., and National Institutes of Health Grant AI-23253 to J. G. Hildebrand (University of Arizona). We are grateful to P. Randolph for excellent technical assistance. We thank R. Booker for supplying M. sexta, A. A. Osman for insect rearing, R. M. Harris-Warrick and A. R. Willms for helpful discussions, J. G. Hildebrand for supporting our work, B. Johnson for valuable comments to this manuscript, and D. P. McCobb, W. W. Webb, R. M. Williams, and W. R. Zipfel for the privilege of using their equipment. Special thanks go to L. Davenport.

Correspondence should be addressed to Dr. Peter Kloppenburg, Cornell University, Section of Neurobiology and Behavior, Seeley G. Mudd Hall, Ithaca, NY 14853. Copyright (C) 1999 Society for Neuroscience 0270-6474/99/198172-10\$05.00/0
}

MGC contains the arbors of a single 5-HT-immunoreactive neuron (Kent et al., 1987; Homberg and Hildebrand, 1989). Synaptic contacts between the 5-HT neuron and other cells in the AL are predominantly output synapses from the 5-HT-containing cell (Sun et al., 1993). Recently, we reported that exogenously applied 5-HT increases cell excitability, broadens action potentials, and increases the cell input resistance of many AL neurons in situ (Kloppenburg and Hildebrand, 1995) and that these effects can be mimicked by the application of 5-HT to Manduca AL neurons in primary cell culture (Mercer et al., 1996). In agreement with its effects on cell excitability and spike waveform, in vitro studies revealed that 5-HT leads to a reduction in the amplitude of voltage-gated $\mathrm{K}^{+}$currents in Manduca AL neurons (Mercer et al., 1995, 1996). However, the functional significance of these modulatory effects remains unclear, in part at least, because the effects of 5-HT on responses elicited by biologically relevant odors, such as pheromones and host plant odors, have yet to be tested.

Here we examine the effects of 5-HT on the responses of an identified population of MGC projection neurons (MGC-PNs) to female sex pheromone. MGC-PNs form the principal output pathway from the MGC to higher-order centers of the brain (Homberg et al., 1988, 1989), and they play an important role in the coding of pheromonal information (Christensen and Hildebrand, 1987; Christensen et al., 1989, 1996; Hansson et al., 1991). We have devised a method that allows us to study in the same cells both the effects of 5-HT on responses of MGC-PNs to pheromone and the mechanisms via which 5-HT operates.

This paper addresses three important issues. First, does 5-HT alter the responses of MGC-PNs to pheromonal signals? Second, how are these changes mediated at the cellular level? And third, 
do reported shifts in activity, including the performance of odordriven behaviors, such as mating (Gilmore, 1938; Lingren et al., 1977), coincide with changes in the 5-HT content of the ALs?

\section{MATERIALS AND METHODS}

Materials. Manduca sexta (Lepidoptera: Sphingidae) were held at $25^{\circ} \mathrm{C}$ and $50-60 \%$ relative humidity under a long-day photoperiod regimen (14:10 hr light/dark) and reared on an artificial diet [modified from that of Bell and Joachim (1976)]. In an attempt to perform all experiments on animals in a reproducible physiological state, we prepared all moths the evening before the day on which they were used. Each moth was immobilized in a plastic tube (Christensen and Hildebrand, 1987), the scales were removed from its head, and the insect was kept at room temperature $\left(\sim 20^{\circ} \mathrm{C}\right)$ overnight. Before opening the head capsule, the animals were anesthetized by cooling on ice or in a refrigerator $\left(\sim 4^{\circ} \mathrm{C}\right)$ for $20-30 \mathrm{~min}$. All chemicals, unless stated otherwise, were obtained from Sigma (St. Louis, MO).

In situ preparations. Intact brains, semi-intact brain preparations, and brain slices were used for whole-cell patch-clamp recordings from MGC projection neurons in situ. These preparations were similar to those used with the spiny lobster (Wachowiak and Ache, 1994; Wachowiak et al., 1996) and the honey bee (Kloppenburg et al., 1999) and are comparable also with patch-clamp recordings in vertebrate slice preparations (Edwards et al., 1989; Sakmann et al., 1989).

Intact brain preparation. By the use of intact brains, the antennae, as well as the entire neuronal network, were left intact. Shortly before the experiment, the head capsule was opened by cutting a window between the two compound eyes and the bases of the antennae. The brain was exposed by removing the palps, cibarial pump, and antennal muscles. The head was then removed from the rest of the animal and pinned in a Sylgard-coated recording chamber (volume, $\sim 1 \mathrm{ml}$ ). To gain access to the recording site and facilitate the penetration of pharmacological agents into the tissue, we desheathed parts of the AL using fine forceps.

Semi-intact brain preparation. To improve access to the recording site and its visualization, semi-intact brain preparations were also used. After the steps described above for intact brain preparations were followed, the brain with antennal nerves and antennae attached was dissected from the head capsule and transferred to a small recording chamber containing insect saline. After the brain was secured in place, it was often advantageous to remove parts of the brain or to perform recordings from isolated antennal lobes to improve visualization of the cell bodies and of the recording pipette.

Brain slices. Brain slices offer two principal advantages; first, visibility of the recording site and the electrode is improved, and second, drugs gain more rapid and more direct access to the cells under investigation. It is also possible, by the use of brain slices, to record from neurites under visual control. Two methods were used to obtain brain slices. Either the brain was dissected out of the head capsule, embedded in a lowtemperature agarose (SeaPlaque or SeaPrep agarose; FMC Bioproducts, Rockland, ME) dissolved in saline, and cut into slices $\sim 200 \mu \mathrm{m}$ thick using a vibratome (series 1000; Technical Products, St. Louis, MO), or the whole head capsule was removed and sectioned using the vibratome, leaving the antennae and antennal nerves intact. Although it is possible to obtain sections with the antennal nerves and both antennae intact, the number of preparations that show reliable neuronal responses to odor is somewhat reduced in brain slices compared with that in the intact and semi-intact brain preparations.

AL neurons were visualized using a fixed-stage upright microscope (Olympus, Mellville, NY, or Zeiss, Thornwood, NY) equipped with Hoffmann modulation optics (Greenvale, NY) and long-working distance objectives $(30 \times$ air or $40 \times$ water immersion) or an inverted microscope (Olympus or Zeiss) equipped with Hoffmann modulation optics $(40 \times)$. To increase the chance of obtaining a high-quality seal between the recording electrode and the cell body chosen for analysis, we cleaned the surface of the cell with a small stream of saline pressure ejected from a large-diameter pipette and/or by a stream of pipette solution ejected from the recording pipette. Brief enzyme treatment (collagenase, $0.5 \mathrm{mg} / \mathrm{ml}$; dispase, $2 \mathrm{mg} / \mathrm{ml}$ in saline; Life Technologies, Gaithersburg, MD) was also used for this purpose in some preparations. During the experiments, the preparation was superfused constantly with saline solution $\left(\sim 2 \mathrm{ml} / \mathrm{min}^{-1}\right)$ modified from Pichon et al. (1972) and as used previously for voltage-clamp analysis of AL neurons in vitro (Mercer et al., 1995, 1996) containing (in $\mathrm{mM}$ ): $150 \mathrm{NaCl}, 4$ $\mathrm{KCl}, 6 \mathrm{CaCl}_{2}, 5 \mathrm{D}$-glucose, and 10 HEPES, adjusted to $\mathrm{pH} 7$ and 360
mOsm. 5-HT (serotonin creatinine sulfate; Sigma or Research Biochemicals, Natick, MA) was added to the superfusion saline at a final concentration of $10^{-4} \mathrm{M}$. The threshold for detectable excitation of projection neurons in situ is $10^{-5} \mathrm{M}$, and a maximal effect is observed at $10^{-4} \mathrm{M}$ (Kloppenburg and Hildebrand, 1995).

Whole-cell recordings. Whole-cell recordings in current and voltage clamp were made from cell somata using patch-clamp recording techniques (Hamill et al., 1981). Electrodes with resistances of 2-4 M $\Omega$ were made from borosilicate glass (100 $\mu \mathrm{l}$ micropipettes; outer diameter of $1.71 \mathrm{~mm}$; inner diameter of $1.32 \mathrm{~mm}$; VWR Scientific, West Chester, CA) using a Flaming-Brown puller (p-87; Sutter Instrument, San Rafael, $\mathrm{CA}$ ) and were filled with a solution containing (in $\mathrm{mM}$ ): $150 \mathrm{~K}$-aspartate, $10 \mathrm{NaCl}, 2 \mathrm{MgCl}_{2}, 1 \mathrm{CaCl}_{2}, 10$ EGTA, and 5-10 HEPES, adjusted to $\mathrm{pH}$ 7 and 330 mOsm. Recordings were made using an AxoPatch 200B or 1D amplifier (Axon Instruments, Foster City, CA), and the data were acquired using pCLAMP6 software and a TL1 analog-to-digital board (Axon Instruments) run on a Gateway 2000 4DX2-66V spacecow microcomputer. Stimulus protocols used in this study are presented alongside the results, where appropriate. Membrane currents sampled at intervals of $100 \mu \mathrm{sec}$ were filtered at $2 \mathrm{kHz}$ using a low-pass four-pole Bessel filter. Junction potentials were nullified before seal formation. Pipette and membrane capacitances were compensated. Series resistance compensation was applied (60-80\%). Additionally, in most recordings a $\mathrm{P} / 6$ protocol (see Armstrong and Bezanilla, 1974) was used for digital subtraction of leak and capacitive currents.

Histology. Lucifer yellow (Aldrich, Milwaukee, WI), biocytin (Sigma), or neurobiotin (Vector Laboratories, Burlingame, CA) added to the recording electrode $(0.1-0.5 \%)$ was used to stain cells. During the recording period, sufficient dye entered the cells through the lowresistance patch pipettes without applying iontophoretic current. Preparations with stained neurons were processed using standard histological protocols (see Heinbockel et al., 1998).

Current isolation. Membrane currents were isolated using a combination of pharmacological blockers, voltage inactivation, and digital current subtraction protocols, based on protocols that have been shown to be effective on cultured Manduca AL neurons (Mercer et al., 1995, 1996). Sodium currents were blocked by tetrodotoxin (TTX; $10^{-7}-10^{-4} \mathrm{M}$ ). Calcium currents were blocked by $\mathrm{CdCl}_{2}\left(10^{-6}-5 \times 10^{-4} \mathrm{M}\right)$. Tetraethylammonium (TEA; $\left.2-3 \times 10^{-2} \mathrm{M}\right)$ was used to block $I_{\mathrm{K}(\mathrm{V})}$ and also a $\mathrm{Ca}^{2+}$-activated outward current $\left[I_{O(\mathrm{Ca})}\right] . I_{O(\mathrm{Ca})}$ was also indirectly eliminated when the $\mathrm{Ca}^{2+}$ currents were blocked by $\mathrm{CdCl}_{2}$. The transient $\mathrm{K}^{+}$current $I_{A}$ was blocked with 4-aminopyridine (4-AP; 4-5 $\times$ $10^{-3} \mathrm{M}$ ) or, alternatively, was eliminated by holding the MGC projection neurons at $-40 \mathrm{mV}$, where $I_{A}$ is $\sim 90 \%$ inactivated (see Fig. $5 C$ ).

To measure steady-state activation, incrementing voltage steps were applied from a constant holding potential (for details see voltage protocols provided in Figs. $5 A, 6 A)$. The voltage dependence of $I_{A}$ and $I_{\mathrm{K}(\mathrm{V})}$ was determined by converting the peak currents to peak conductances, $g$ values, which were scaled as a fraction of the calculated maximal conductance. The $\mathrm{K}^{+}$equilibrium potential $\left(E_{\mathrm{K}}=-91.6 \mathrm{mV}\right.$; for $\left.20^{\circ} \mathrm{C}\right)$ was calculated using the Nernst equation, assuming the intracellular $\mathrm{K}^{+}$ concentration equals the $\mathrm{K}^{+}$concentration in the pipette solution.

The resulting conductance/voltage $(g / \mathrm{V})$ curve was fitted to a thirdorder $(n=3)$ and first-order $(n=1)$ Boltzmann equation of the form:

$$
g / g_{\max }=1 /\left(1+\mathrm{e}^{-\left(\mathrm{V}-\mathrm{V}_{0.5}\right) / \mathrm{s}}\right)^{\mathrm{n}}
$$

where $g_{\max }$ is the maximal conductance and $s$ is a slope factor. For the third-order Boltzmann fit, $\mathrm{V}_{0.5}$ is the voltage at which half-maximal activation of the individual gating steps occurs, assuming a third-order activation relation (see Hodgkin and Huxley, 1952). For the first-order Boltzmann fit, $\mathrm{V}_{0.5}\left(=\mathrm{V}_{0.5}\right.$ act $)$ is the voltage of half-maximal activation of the peak current.

Steady-state inactivation of $I_{A}$ was measured from a holding potential of $-60 \mathrm{mV}$. Voltage presteps of $2 \mathrm{sec}$ duration were delivered at $10 \mathrm{mV}$ increments from -90 to $-20 \mathrm{mV}$, followed by a step to $+20 \mathrm{mV}$ (see Fig. $5 B$ ), and the peak current was measured. The data, scaled as a fraction of the calculated maximal conductance, were fitted to a firstorder Boltzmann equation (Eq. 1 with $n=1$ ), based on the model of Hodgkin and Huxley (1952) where $\mathrm{V}_{0.5}$ is the voltage for half-maximal inactivation $\left(\mathrm{V}_{0.5_{\text {inac }}}\right)$.

Cell-attached patch-clamp recordings. Cell-attached recordings with low seal resistance (several megaohms) were used to monitor the spike frequency of identifiable cells over prolonged periods $(>1 \mathrm{hr})$ without damage. This configuration is comparable with techniques used, e.g., by Häusser and Clark (1997). The patch pipette was filled with extracellular 
Figure 1. A, Bodian stain of a section through the antennal lobe showing the glomerular structure of the antennal-lobe neuropil and clusters of cell bodies at the periphery. $B$, The framed cell body cluster from $A$ shown in higher magnification. $C$, In situ preparation of the antennal lobe showing a cell body cluster similar to that shown in $A$ and $B$. $D$, Patch pipette in recording position on one of the cell bodies. Scale bars: $A, 100 \mu \mathrm{m} ; B, 50 \mu \mathrm{m} ; C, 25$ $\mu \mathrm{m} ; D, 12.5 \mu \mathrm{m}$.

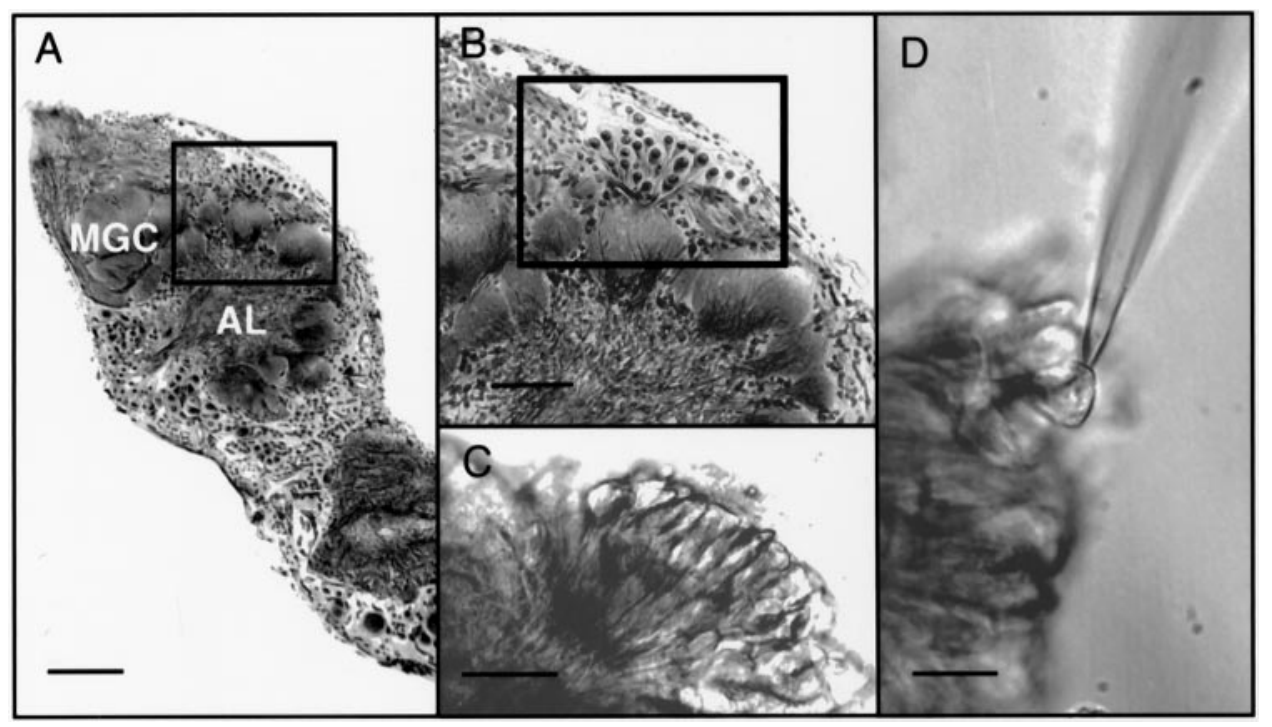

saline or intracellular pipette solution. Spikes were recorded in voltage clamp. Low seal resistances were not considered a problem, as long as the signal-to-noise ratio enabled spike detection. These recordings were used to investigate the effects of 5-HT on odor-induced responses before 5-HT modulation of ionic currents in the same cells was examined using whole-cell patch-clamp recording techniques.

Data analysis. For electrophysiological data analysis, the software programs pCLAMP6 (Axon Instruments), Axograph3 (Axon Instruments), and Delta Graph (Delta Point, Monterey, CA) were used. Student's $t$ tests were used to assess the significance of differences between mean values of parameters measured under control conditions, during 5-HT application, and after washing in 5-HT-free saline. A Bonferroni correction was used to adjust for repeated $t$ tests, and significance was accepted at $p=0.025$.

Odor stimulation. The antenna ipsilateral to the recording electrode was stimulated with air carrying the pheromone. Neurons that also responded to clean air were not included in this study. Odor stimuli were delivered to the antenna by pulsing air from a compressed air cylinder through cartridges containing filter paper impregnated with the odorant. Odor delivery and preparation of the cartridges are described in detail elsewhere (Heinbockel et al., 1998). The pheromone was extracted by a hexane wash of the female pheromone gland as described previously (Christensen and Hildebrand, 1987). To prevent sensory adaptation to olfactory stimuli, an interstimulus interval of at least 1 min was used.

HPLC. Single ALs were assayed for 5-HT using reverse-phase HPLC with electrochemical detection. Each AL was dissected from the brain, transferred into an Eppendorf tube containing $50 \mu \mathrm{l}$ of ice-cold $0.4 \mathrm{M}$ perchloric acid, $2.6 \mathrm{~mm}$ sodium metabisulphite, and $2.7 \mathrm{mM}$ EDTA disodium salt, and frozen in liquid nitrogen. Samples were stored at $-80^{\circ} \mathrm{C}$ for no longer than 3 weeks before use. The samples were sonicated for $\sim 10 \mathrm{sec}$ and then centrifuged at $18,200 \times g$ for $20 \mathrm{~min}$ at $4^{\circ} \mathrm{C}$. The supernatant from each sample $(20 \mu \mathrm{l})$ was injected directly onto the column. The HPLC system consisted of a Shimadzu LC-6A pump, a Rheodyne injector, a $\mathrm{C}_{8}$ column $(100 \times 4.6 \mathrm{~mm} ; 5 \mu \mathrm{m}$ packing particles $)$, and an ESA model 5100A coulometric detector. The mobile phase used to elute 5 -HT contained $31.2 \mathrm{gm} / \mathrm{min}$ of sodium dihydrogen orthophosphate, $3.2 \mathrm{gm} / \mathrm{min}$ of anhydrous sodium acetate, $0.22 \mathrm{gm} / \mathrm{min}$ of EDTA, and $0.54 \mathrm{gm} / \mathrm{min}$ of octanesulphonic acid (sodium salt) mixed with $200 \mathrm{ml}$ of acetonitrile. Milli-Q water was added, and the $\mathrm{pH}$ was adjusted to 2.5 with phosphoric acid before the final solution was made up to 21 with milli-Q water. The mobile phase was filtered and degassed before use and during the assays was pumped at a flow rate of $1.5 \mathrm{ml} / \mathrm{min}$. The detector was set at a working potential of $+0.6 \mathrm{~V}$. 5-HT and $N$-acetyl-5-HT standards were run at the beginning and at intervals throughout each assay run.

Levels of 5-HT in the ALs are expressed as an amount per microgram of protein. Protein measurements were determined using a modification (Peterson, 1977) of the technique described by Lowry et al. (1951). The assays were conducted on the pellets obtained after centrifugation of AL samples for HPLC. The pellets were dissolved in $1 \mathrm{~N} \mathrm{NaOH}$ containing $2.5 \%$ SDS. Dilutions of bovine serum albumin were used as standards.
Measurements of the amount of protein in each pellet were repeated twice in duplicate. The recorded value was the average of these four measurements.

Two sets of samples were analyzed, each of which included at least seven time points over a period of $24 \mathrm{hr}$. For each run, a minimum of four (maximum of six) individuals was examined at each time point. The data were analyzed by ANOVA using the statistical analysis system general linear model procedure. Contrast analysis was used to examine the significance of trends apparent in the two data sets, which were combined for this purpose.

\section{RESULTS}

The modulatory effects of exogenously applied 5-HT on identified olfactory projection neurons in the macroglomerular complex of the male moth Manduca sexta were investigated in situ. The effects of 5-HT on responses induced by a well defined, physiologically relevant odor (sex pheromone) and on voltage-activated $\mathrm{K}^{+}$currents were examined in the same cells. MGC-PNs were identified both by their electrophysiological responses to pheromone stimulation and by their morphological characteristics, revealed by intracellular staining.

\section{5-HT effect on pheromone-induced responses of MGC-PNs}

Current-clamp recordings were made with patch pipettes from neurites in the neuropil of the MGC or from somata located in clusters outside the neuropil (Fig. 1). Projection neurons of the MGC responded to pheromone stimulation of the ipsilateral antenna with membrane depolarization, typically leading to a burst of action potentials, which was then followed by an afterhyperpolarization (Fig. 2A) (see Christensen and Hildebrand, 1987; Christensen et al., 1989, 1996; Hansson et al., 1991; Heinbockel et al., 1998).

The principal effects of 5-HT were a depolarization of the resting membrane potential by $4.3 \pm 1.8 \mathrm{mV}(n=8)$ and an increase in the excitatory components of the pheromone-induced response. These effects were fully developed after an $\sim 3-5$ min bath application of 5-HT. No further change was observed, even when 5-HT was applied over a period of $>10 \mathrm{~min}$. In all recordings, responses started to return to control levels within 1-3 min, when 5-HT was replaced by normal saline. In most recordings, full recovery was observed within 15-30 min. However, in some cases, full recovery was not accomplished within the recording time (up to $40-50 \mathrm{~min}$ after starting the wash). Figure 2 shows 

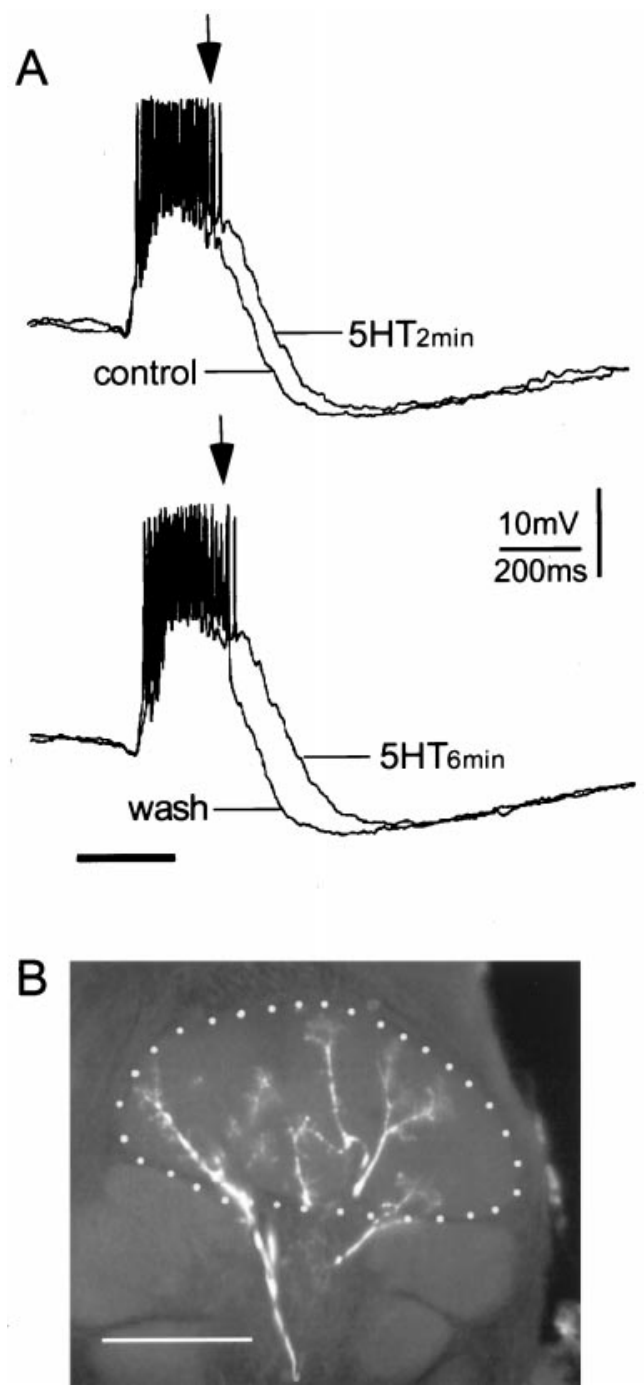

Figure 2. A, Whole-cell patch-clamp recording of responses of an MGC projection neuron to antennal stimulation with pheromone before (control), during (2 and $6 \mathrm{~min})$, and after (wash) application of 5-HT $\left(10^{-4} \mathrm{M}\right)$. The resting membrane potential was held at the control value by tonic current injection. Arrows indicate the positions of the last spike from the control trace (top) and the wash trace (bottom). 5-HT increased the number of spikes, the length of the spike train, and the duration of the depolarization elicited by stimulation with pheromone. These effects of 5-HT were reversible. The horizontal bar beneath the two recordings marks the duration of pheromone stimulation. $B$, Arborizations of the projection neuron within the cumulus (marked with the dotted line) of the MGC revealed by intracellular staining. Scale bar, $50 \mu \mathrm{m}$.

examples of pheromone-induced responses from an MGC-PN before, during, and after application of 5-HT. Serotonin increased the duration of membrane depolarization and the number of action potentials recorded during stimulation of the ipsilateral antennae with pheromone.

To quantify the effects of 5-HT, percentage changes in the number of action potentials recorded during pheromonal stimulation and the time between the first and last action potential of the response were measured (Fig. $3 A$ ). Because cell excitability is affected also by changes in resting membrane potential, tonic current injection was used in these experiments to hold the resting potential as close as possible to the value recorded before 5-HT application. In the presence of 5-HT, the number of action
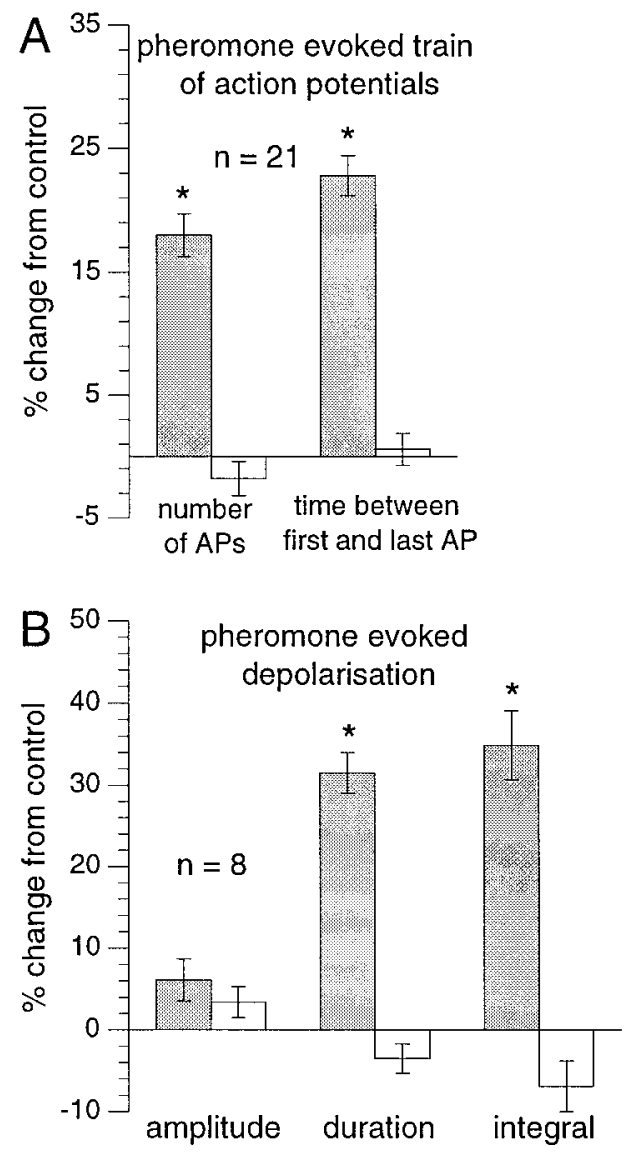

Figure 3. Effects of 5-HT on several parameters of the response of MGC projection neurons to pheromone. A, Mean percentage change in the number of spikes and the length of the spike train. In the presence of 5-HT (gray vertical bars), the number of spikes and the length of the spike train were increased significantly, by $18 \pm 2 \%(p<0.0001)$ and $23 \pm 2 \%$ $(p<0.0001)$, respectively. Both effects showed significant recovery after washing with saline (white vertical bars; $p<0.0001$ ). $B$, Mean percentage change of the slow component of pheromone-evoked depolarization. 5-HT had no significant effect on the amplitude of the depolarization but increased significantly the length and the integral of the response, by $32 \pm$ $2 \%(p<0.0001)$ and $35 \pm 4 \%(p<0.0001)$, respectively (gray vertical bars). Both effects were reversible after washing with saline (white vertical bars; $p<0.0001) .{ }^{*}$ indicates significantly different from control $(p \leq$ 0.025). $A P$, Action potential.

potentials was increased by $18 \pm 2 \%(p<0.0001 ; n=21)$, and the duration of the burst was increased by $23 \pm 2 \%(p<0.0001$; $n=21$ ). Both effects were reversed by washing with 5 -HT-free saline. To analyze the effect of 5-HT on the slow component of the response (membrane depolarization), we low-pass filtered the response (see Olsen and Calabrese, 1996). By eliminating fast voltage transients, such as action potentials, this procedure allows separate analysis of slower changes in membrane potential. The following parameters of pheromone-induced depolarizations were measured: (1) peak amplitude, (2) time from the onset of depolarization to return to baseline, and (3) the integral from onset of depolarization to the point at which the potential returned to baseline. These data are summarized in Figure $3 B$. The duration of the odor-induced membrane depolarization was increased by $32 \pm 2 \%(p<0.0001 ; n=8)$, and the integral of the depolarization was increased by $35 \pm 4 \%(p<0.0001 ; n=8)$. A slight increase in depolarization amplitude was not statistically significant. 

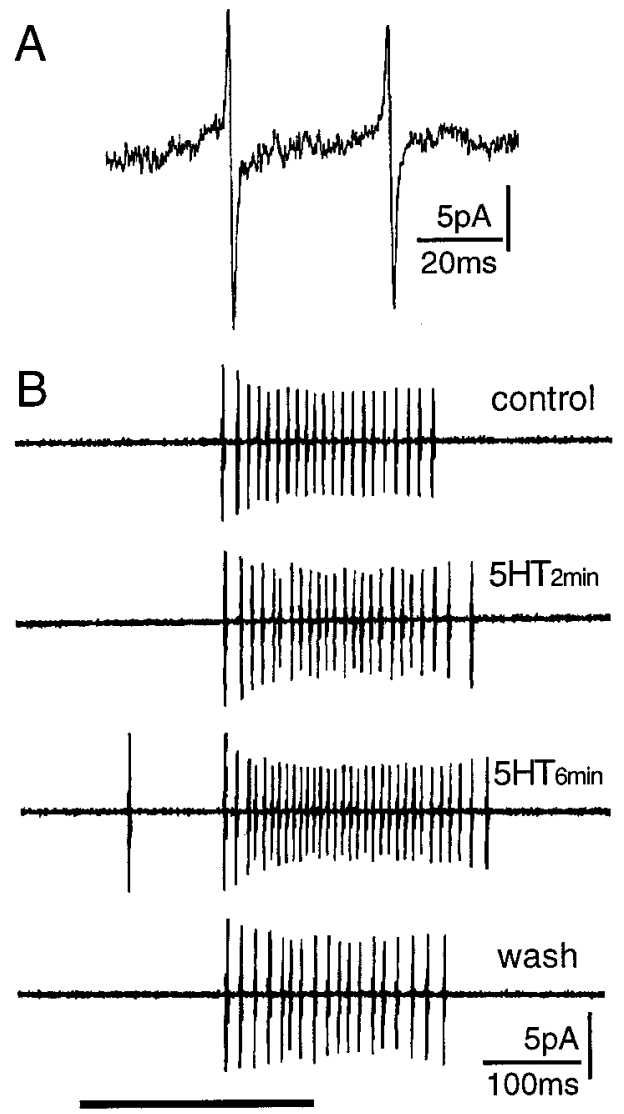

Figure 4. A, Action potentials recorded from the cell body of an MGC projection neuron using voltage-clamp recording in cell-attached configuration. $B, 5$-HT effect on the pheromone response of an MGC projection neuron recorded as described in $A$. The horizontal bar beneath the recording indicates the duration of pheromone stimulation. 5-HT increased reversibly the number of action potentials and the length of the spike train elicited by the pheromone. Recordings were high-pass-filtered on-line to eliminate slow components of the signal. This type of recording was used to identify pheromone-sensitive neurons and to test whether pheromone-induced responses were modulated by 5-HT. A whole-cell recording configuration was then established to examine the effects of 5-HT on voltage-gated $\mathrm{K}^{+}$currents in the same cells.

\section{Voltage-gated $\mathrm{K}^{+}$currents}

On the basis of previous studies performed on Manduca AL neurons in primary tissue culture (Mercer et al., 1995, 1996), we hypothesized that modulation of voltage-activated $\mathrm{K}^{+}$currents by 5 -HT might cause or contribute to the increase in excitability observed in MGC-PNs in situ. To test whether $\mathrm{K}^{+}$currents are indeed the target of modulation by 5-HT, voltage-clamp studies were performed on MGC-PNs using whole-cell patch-clamp recordings in situ. The data on $\mathrm{K}^{+}$currents presented in this paper were all obtained from neurons identified as MGC-PNs. Electrophysiological responses of the cells to pheromone stimulation were characterized using recordings in cell-attached mode (Fig. 4) before the whole-cell recording configuration was established. Intracellular staining via the patch pipette while recording whole cell was used to confirm that each recorded neuron was indeed an MGC-PN. The combined approach of using cell-attached and whole-cell recordings in intact, semi-intact, or slice preparations provided us with the opportunity to examine, in the same cells, the modulatory effects of 5-HT on responses to physiologically relevant stimuli (pheromones), as well as the cellular mechanisms involved.
Figure $4 A$ shows action potentials recorded in cell-attached mode from the cell body of an MGC-PN. The action potentials do not arise from ion channel activity within the patch but rather are the result of capacitive currents invading the patch as a result of action potentials generated elsewhere on the cell. Figure $4 B$ shows responses to pheromone measured cell-attached in voltageclamp mode before, during, and after the application of 5-HT. Slow components of the signal have been subtracted digitally. The effects of 5-HT are similar to those observed using whole-cell current-clamp recordings (see Fig. 2). 5-HT increased the number of spikes and the time between the first and the last spike of the response. In contrast to many intracellular recordings (see Christensen and Hildebrand, 1987; Christensen et al., 1989, 1996; Hansson et al., 1991; Heinbockel et al., 1998) we typically saw no or a very low spontaneous activity in these cell-attached recordings.

At least two voltage-activated $\mathrm{K}^{+}$currents were apparent in all MGC-PNs: a transient $\mathrm{K}^{+}$current $\left(I_{A}\right)$ and a sustained $\mathrm{K}^{+}$ current $\left[I_{\mathrm{K}(\mathrm{V})}\right]$. Similar $\mathrm{K}^{+}$currents have been described previously in cultured AL neurons from Manduca sexta (Mercer et al., 1995, 1996). Both currents have differential (concentrationdependent) sensitivity to standard pharmacological tools including 4-AP, TEA, and quinidine (Mercer et al., 1995, 1996) (P. Kloppenburg, unpublished observation) and have differences in their steady-state voltage inactivation. Currents were isolated using a combination of pharmacological blockade, appropriate holding potential, and current subtraction protocols. Further details are provided in the text describing the currents. Current profiles that were clearly dominated either by $I_{A}$ or $I_{\mathrm{K}(\mathrm{V})}$ as a result of using these current isolation protocols may still have included small residuals of other currents. It seems likely that the currents we have measured originate primarily from the cell body. Ionic currents generated by channels selectively located in very distal regions of the neuron may not be detectable by voltage clamp of the soma.

\section{Transient $\mathrm{K}^{+}$current}

For measurement of $I_{A}$, the preparation was bathed in saline containing $10^{-7}-10^{-4} \mathrm{M}$ TTX, 2-3 $\times 10^{-2} \mathrm{M}$ TEA, and 2-6 $\times$ $10^{-4} \mathrm{M} \mathrm{Cd}^{2+}$ to reduce greatly non- $I_{A}$ currents. Under control conditions, $I_{A}$ starts to activate at voltages of approximately -40 $\mathrm{mV}$ (Fig. 5A,C). The current is transient and decays because of inactivation during a maintained depolarizing voltage step. The conductance/voltage relation (Fig. $5 C$ ) was constructed using the peak currents evoked by each voltage step. This curve shows a typical voltage dependence for activation of $I_{A}$ and was fitted to a third-order Boltzmann equation (Eq. 1) based on the model from Hodgkin and Huxley (1952). This fit shows half-maximal activation for each of the individual gating steps at $-32.7 \mathrm{mV}$, leading to half-maximal activation of the peak current at $-8.8 \pm 1.8 \mathrm{mV}$ $(n=4)$. Serotonin decreased the amplitude of $I_{A}$ (Fig. $5 A$ ), significantly reducing the maximal conductance by $25 \pm 6 \%(p<$ $0.025 ; n=4$; Fig. $5 C$ ). There was no significant shift in the voltage dependence of activation [see scaled curve (5-HT*) in Fig. $5 C$ ].

The voltage dependence of inactivation of $I_{A}$ (Fig. $5 B, D$ ) is well fitted by a first-order Boltzmann equation (Eq. 1). The voltage for half-maximal inactivation under control conditions was $-53.3 \pm$ $2.0 \mathrm{mV}(n=5)$. The curve for steady-state inactivation was shifted by 5 -HT to more negative potentials (Fig. $5 D$ ), changing 

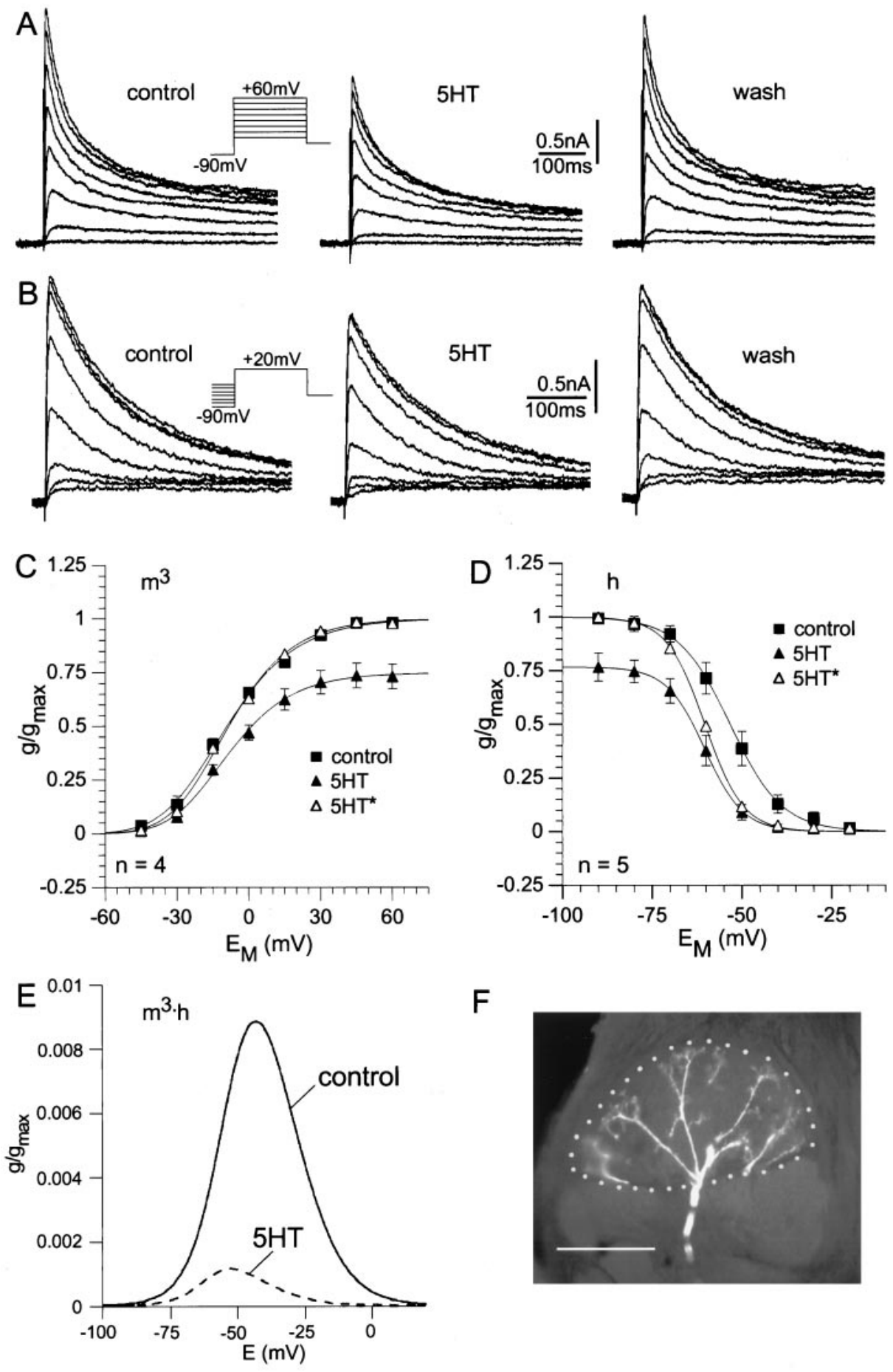

F

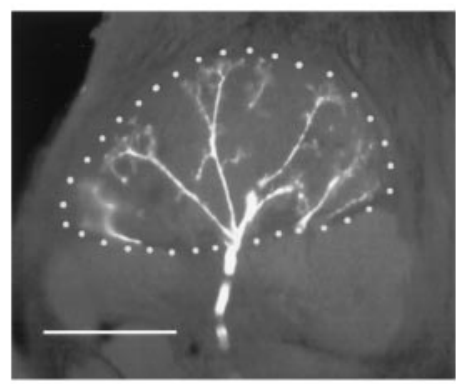

Figure 5. Voltage-clamp analysis of the effect of 5-HT on the transient potassium current $\left(I_{A}\right)$ in MGC projection neurons. All cells responded to pheromone in the pretest, and the responses were enhanced by 5 -HT. The whole-cell configuration was established after the 5-HT effect of the pretest had fully reversed. $I_{A}$ was isolated pharmacologically and by digital subtraction (see Materials and Methods). $A$, Steady-state activation. Current traces of $I_{A}$ before, during, and after application of 5-HT are shown. The holding potential was $-60 \mathrm{mV}$. After a prepulse to $-90 \mathrm{mV}(2 \mathrm{sec})$, voltage was stepped from -45 to $+60 \mathrm{mV}$ in $15 \mathrm{mV}$ increments. $B$, Steady-state inactivation. Current traces of $I_{A}$ before, during, and after application of 5-HT are shown. The holding potential was $-60 \mathrm{mV}$. Test pulses (to +20 $\mathrm{mV}$ ) were preceded by $2 \mathrm{sec}$ preconditioning pulses between -90 and $-20 \mathrm{mV}$ in 10 $\mathrm{mV}$ increments. $C, D$, Conductance/voltage curves for activation $\left(C ; \mathrm{m}^{3}\right)$ and inactivation $(D ; h)$ of $I_{A}$ under control conditions (solid squares) and in $10^{-4} \mathrm{M} 5-\mathrm{HT}$ (solid triangles). The open triangles (5-HT*) represent the conductance under 5-HT scaled to the control. Values are means $\pm \operatorname{SEM}(n=$ 4 for activation; $n=5$ for inactivation), calculated as a fraction of the calculated maximal conductance under control conditions in each experiment. $C$, Steady-state activation. The curves are fits to a third-order Boltzmann relation (Eq. 1, Materials and Methods) with the following parameters. Control: $\mathrm{V}_{\text {act }}=-32.69 \mathrm{mV} ; s_{\text {act }}=-17.51$; 5-HT: $\mathrm{V}_{\text {act }}=-29.85 \mathrm{mV} ; s_{\text {act }}=-15.99 . D$, Steady-state inactivation. The curves are fits to a first-order Boltzmann relation (Eq. 1, Materials and Methods) with the following parameters. Control: $\mathrm{V}_{0.5}=-53.3 \mathrm{mV}$; $s_{\text {inact }}=7.23 ; 5-\mathrm{HT}: \mathrm{V}_{0.5_{\text {inact }}}=-60.4 \mathrm{mV}$; $s_{\text {inact }}=5.35 . E$, To demonstrate the decrease in tonically active $I_{A}$ near the resting potential, the product of the activation and inactivation curves (from $C, D$ ) plotted as follows: $g / g_{\max }=\left(1 / 1+\mathrm{e}^{\left.-\left(\mathrm{V}-\mathrm{V}_{0.5_{\mathrm{san}} \mathrm{x}}\right) / \mathrm{s}_{\mathrm{sat}}\right)^{3}} \times(1 / 1\right.$ $+\mathrm{e}^{\left.-\left(\mathrm{V}-\mathrm{V}_{0.5 \mathrm{max}}\right) / \mathrm{s}_{\max }\right)^{1}}$ for the control condition and for 5-HT application. These curves showed the fraction of tonically active $I_{A}$ as a function of the membrane potential. The area between the curve and the baseline is decreased by $88 \%$ during 5 -HT application. $F$, Arborizations of the MGC projection neuron recorded in $A$ revealed by staining via the patch pipette. The cumulus of the MGC is marked by the dotted line. Scale bar, $50 \mu \mathrm{m}$.
$\mathrm{V}_{0.5 \mathrm{inat}}$ from $-53.3 \pm 2 \mathrm{mV}$ under control conditions to $-60.4 \pm$ $0.9 \mathrm{mV}(p<0.01 ; n=5)$ during 5-HT application. This is demonstrated by the scaled curve $\left(5-H T^{*}\right)$ in Figure $5 D$. The effects of 5-HT on $I_{A}$ reversed after washing with normal saline (Fig. 5A,B).

Thus, 5-HT decreased $I_{A}$ by two mechanisms (Fig. 5). First, it significantly decreased the maximal conductance by $25 \%$. Second, it shifted the voltage for half-maximal inactivation to more negative potentials by $7 \mathrm{mV}$ (Fig. $5 D$ ). The shift in $\mathrm{V}_{0.5_{\text {inact }}}$ together with the decrease in $g_{\max }$ would lead to a decrease in the tonically active "window current" between the steady-state activation and inactivation curves. This is demonstrated in Figure $5 E$ by plotting the product of the steady-state activation $\left(\mathrm{m}^{3}\right)$ and inactivation (h) curves. These curves showed the fraction of tonically active $I_{A}$ as a function of membrane potential. Around the normal resting membrane potential of MGC-PNs, tonic $I_{A}$ was dramatically decreased by 5 -HT. For example at $-50 \mathrm{mV}, 5-\mathrm{HT}$ caused an $87 \%$ decrease in resting $I_{A}$.

\section{Sustained $\mathrm{K}^{+}$current}

To measure $I_{\mathrm{K}(\mathrm{V})}$, the preparations were bathed in saline containing $10^{-7}-10^{-4} \mathrm{M} \mathrm{TTX}, 2-6 \times 10^{-4} \mathrm{M} \mathrm{CdCl}_{2}$, and 4-5 $\times$ 


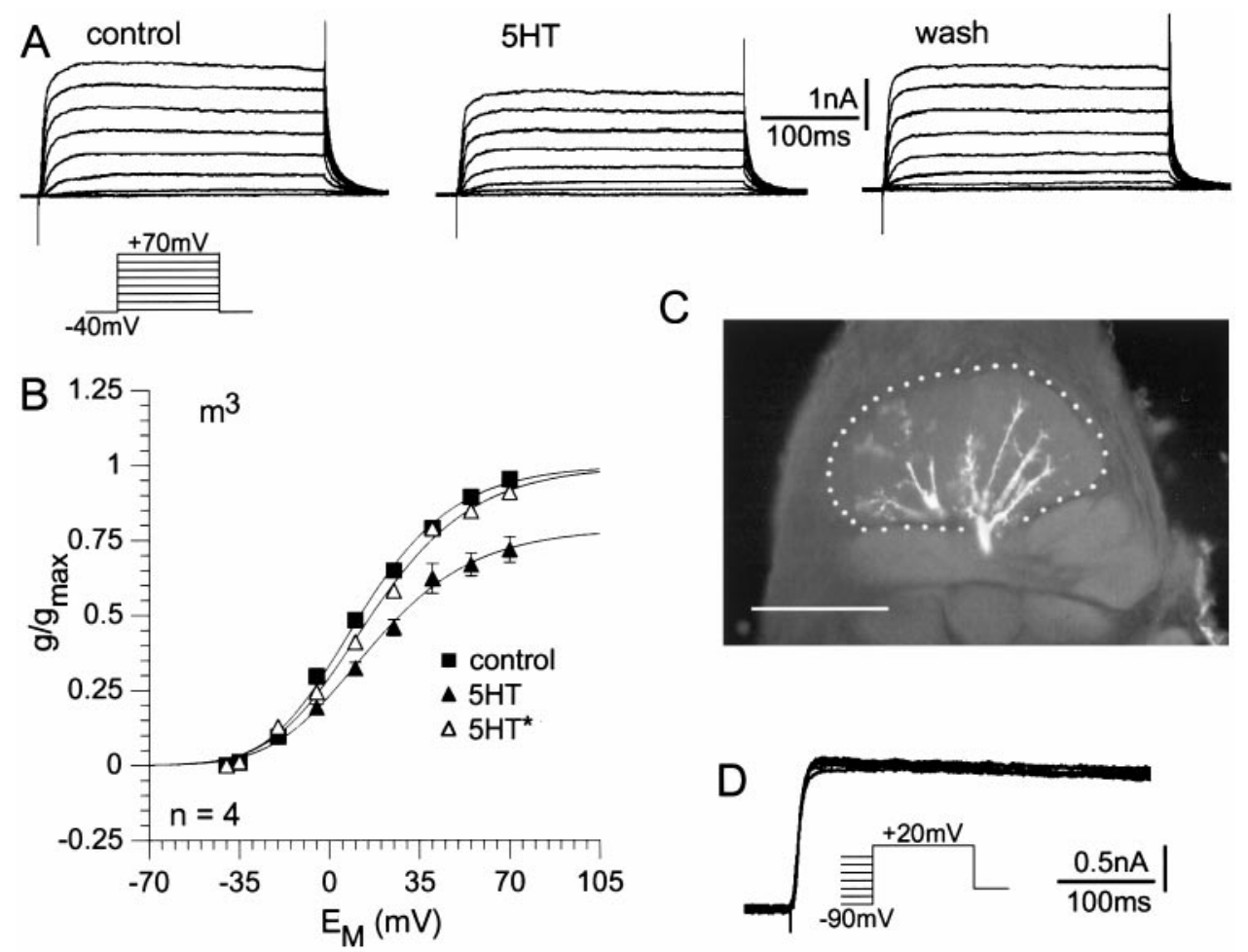

Figure 6. Voltage-clamp analysis of the 5-HT effect on the sustained potassium current $I_{\mathrm{K}(\mathrm{V})}$ in MGC projection neurons. All cells responded to pheromone in the pretest, and the responses were enhanced by 5-HT. The whole-cell configuration was established after the 5-HT effect of the pretest had fully reversed. $I_{\mathrm{K}(\mathrm{V})}$ was isolated pharmacologically or by holding the neuron at $-40 \mathrm{mV}$ where $I_{A}$ is almost completely inactivated. $A$, Steady-state activation. Current traces of $I_{\mathrm{K}(\mathrm{V})}$ before, during, and after application of 5-HT are shown. The holding potential was $-40 \mathrm{mV}$. Voltage was stepped from -35 to $+70 \mathrm{mV}$ in $15 \mathrm{mV}$ increments. $B$, Steady-state activation. Conductance voltage curves for activation under control conditions ( filled squares) and during application of 5-HT ( filled triangles) are shown. The open triangles (5-HT*) represent the conductance under 5-HT scaled to the control. Conductances were calculated assuming $E_{\mathrm{K}}=-91.6 \mathrm{mV}$ (see Materials and Methods). Values are means \pm SEM from four experiments, calculated as a fraction of the calculated maximal conductance under control conditions in each experiment. The curves are fits to a third-order Boltzmann relation (Eq. 1, Materials and Methods) with the following parameters. Control: $\mathrm{V}_{\text {act }}=-18.5 \mathrm{mV} ; s_{\text {act }}=-22.5 ; 5-\mathrm{HT}: \mathrm{V}_{\text {act }}=-16.8 \mathrm{mV} ; s_{\text {act }}=-24.4$. $C$, Arborizations of the MGC projection neuron recorded in $A$ revealed by staining via the patch pipette. The cumulus of the MGC is marked by the dotted line. Scale bar, $50 \mu \mathrm{m}$. $D$, Steady-state inactivation. Current traces of $I_{\mathrm{K}(\mathrm{V})}$ were determined by applying preconditioning pulses ( $\left.2 \mathrm{sec}\right)$ between -90 and $0 \mathrm{mV}$ in $15 \mathrm{mV}$ increments before the test pulses to $+20 \mathrm{mV}$. $I_{A}$ was blocked with $4-5 \times 10^{-3} \mathrm{M} 4$-AP. Data were not plotted because $I_{\mathrm{K}(\mathrm{V})}$ did not show obvious inactivation.

$10^{-3} \mathrm{M} 4$-AP (or the cell was held at $-40 \mathrm{mV}$ ) to block most of the non- $I_{\mathrm{K}(\mathrm{V})}$ currents.

Voltage steps in $15 \mathrm{mV}$ increments between -35 and $+70 \mathrm{mV}$ were delivered to activate $I_{\mathrm{K}(\mathrm{V})}$. Under control conditions, $I_{\mathrm{K}(\mathrm{V})}$ activates with voltage steps above approximately $-35 \mathrm{mV}$ (Fig. $6 A, B)$. The current is sustained and shows minimal decay during a maintained depolarizing voltage step. The conductance/voltage relation (Fig. 6B) was constructed using the maximal currents evoked by each voltage step. This curve shows a typical voltage dependence for activation of $I_{\mathrm{K}(\mathrm{V})}$ and was fitted to a third-order Boltzmann equation (Eq. 1) based on the model from Hodgkin and Huxley (1952). This fit shows half-maximal activation for each of the individual gating steps at $-18.5 \mathrm{mV}$, leading to a half-maximal activation of the peak current at $11.1 \pm 1.4 \mathrm{mV}$ $(n=4)$. Even with depolarizations lasting $1 \mathrm{sec}$ or longer, $I_{\mathrm{K}(\mathrm{V})}$ showed little or no inactivation, and there was no detectable voltage dependence of steady-state inactivation (Fig. 6D). 5-HT decreased the amplitude of $I_{\mathrm{K}(\mathrm{V})}$ (Fig. 6A,B). Although it reduced the maximal conductance significantly by $21 \pm 5 \%(p<0.02$; $n=4$ ), there was no significant shift in the voltage dependence of activation [see scaled curve (5-HT*) in Fig. 6B]. The effect of 5-HT on $I_{\mathrm{K}(\mathrm{V})}$ reversed after washing with 5-HT-free saline (Fig. 6A).

\section{Changing 5-HT levels in the antennal lobes of the moth}

Because the occurrence of pheromone-induced mating behaviors exhibits strong circadian rhythmicity (e.g., Lingren et al., 1977) and 5-HT enhances dramatically the responsiveness of MGC-PN to pheromonal cues, we explored the possibility that time windows in which mating occurs may be accompanied by diel changes in 5-HT levels in the ALs. Both the first and the second set of samples (Fig. 7A,B) used to examine fluctuations in 5-HT levels in the ALs of the moth over a $24 \mathrm{hr}$ period revealed a drop in 5-HT after lights were turned on (lights-ON), followed by an increase in 5-HT levels before lights were turned off (lights-OFF). However, large variations were apparent between individuals at most time points. For this reason, replicate samples from the two runs were combined (Fig. $7 C$ ), and the pooled data were used to examine the significance of trends apparent in the two data sets. Contrast analysis confirmed that 5-HT levels recorded in the middle of the subjective day (the third sampling point in Fig. 7C) are significantly lower $(p=0.0097)$ than peak levels detected around subjective dusk, in this case, $1 \mathrm{hr}$ after lights-OFF (Fig. 7C). The exact timing of peak 5-HT levels in the ALs of the moth varied between individuals. In the first run, 5-HT levels were highest 

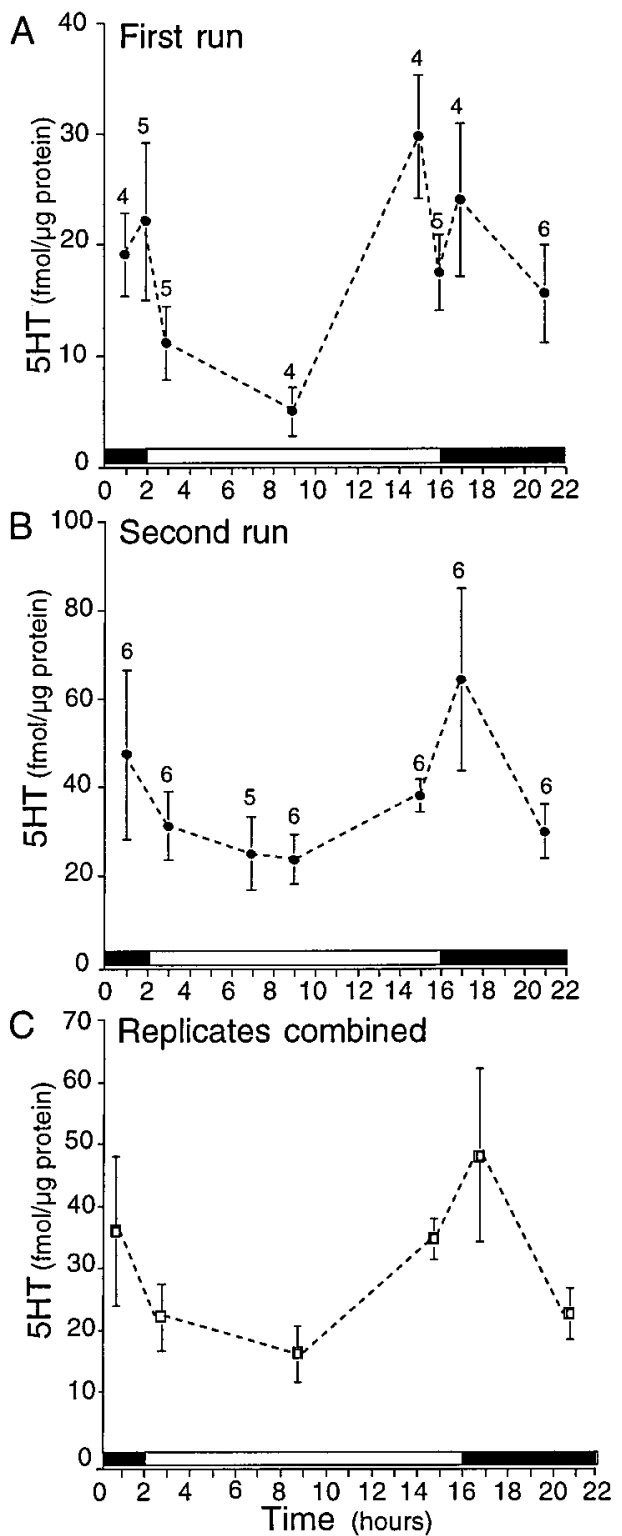

Figure 7. 5-HT levels $( \pm$ SEM) in the antennal lobes of $M$. sexta at different time points over two $24 \mathrm{hr}$ periods. Male moths were maintained for at least $9 \mathrm{~d}$ (at least $7 \mathrm{~d}$ as pupae and $2 \mathrm{~d}$ as adults) under a long-day photoperiod regimen of 14:10 hr (light/dark). Periods during which the light was turned off (black horizontal bars) or on (white horizontal bar) are indicated along the $x$-axis. The $n$ values for each group are provided above the data points. $A, B$ 5-HT levels of the first and second run in which eight and seven time points were examined, respectively. $C$, 5-HT concentrations from the first and second runs combined. Contrast analysis performed on the pooled data confirmed that there is a significant difference between maximum and minimum levels of 5-HT recorded in the antennal lobes of the moth $(p=0.0097)$.

$1 \mathrm{hr}$ before lights-OFF, whereas in the second run, 5-HT levels peaked $1 \mathrm{hr}$ after lights-OFF (Fig. 7A,B). Mean 5-HT levels before lights-ON tended to be higher also than those recorded during the middle of the subjective day (Fig. $7 A-C$ ), but the apparent fall in 5 -HT levels at this time is not statistically significant $(p=0.0952)$.

\section{DISCUSSION}

Here we show for the first time that 5-HT increases the excitatory responses of Manduca MGC-PNs to stimulation of the moth with odorant, in this case, sex pheromone. We show also that over a 24 hr period, 5-HT levels in the AL of the moth fluctuate significantly; they are low during the middle of the subjective day when $M$. sexta is inactive and higher at night, particularly around subjective dawn and dusk, when activity levels, including the levels of odor-driven behavioral activities, are at a peak (Lingren et al., 1977). Taken together, these results suggest that 5-HT is involved in mediating state-dependent changes in olfactory function in the moth.

Using a combination of electrophysiological techniques, we have monitored the modulatory effects of 5-HT on the responses of identified olfactory interneurons to stimulation of the antennae with odorant, as well as investigated, in the same cells, the cellular mechanisms underlying the modulatory actions of this amine. This approach has enabled us to investigate the actions of 5-HT at a number of levels, ranging from its effects on membrane properties to its actions on entire networks in olfactory centers of the moth's brain. A single 5-HT-immunoreactive neuron invades each AL of the moth (Kent et al., 1987). The majority of contacts between 5-HT cell processes and AL neurons are output synapses from the 5-HT-containing cell (Sun et al., 1993), and we assume that exogenously applied 5-HT mimics the effects of 5-HT released from these processes.

The 5-HT-induced increase in the duration of membrane depolarization and the number of action potentials elicited by stimulation with sex pheromone reported here is consistent with our previous findings that 5-HT increases the number and duration of action potentials elicited from AL neurons in situ using electrical stimulation of the olfactory receptor cells (Kloppenburg and Hildebrand, 1995) and from AL neurons in vitro using depolarizing current pulses (Mercer et al., 1995, 1996). 5-HT-induced increases in MGC-PN excitability are caused, at least in part, by a reduction of $\mathrm{K}^{+}$currents in these neurons. $\mathrm{K}^{+}$channels play important roles in setting the resting membrane potential, shaping the action potential waveform, and modulating the frequency of neuronal firing (Salkoff et al., 1992), and it seems likely that 5-HT-induced reduction of $\mathrm{K}^{+}$currents contributes to the changes in resting membrane potential and cell excitability observed in Manduca AL neurons (present investigation) (Kloppenburg and Hildebrand, 1995; Mercer et al., 1995, 1996). In vitro studies of a morphologically identifiable subset of AL neurons have shown that 5 -HT reduces transient, A-type $\mathrm{K}^{+}$currents as well as a sustained $\mathrm{K}^{+}$current that resembles the delayed rectifier $I_{\mathrm{K}(\mathrm{V})}$ (Mercer et al., 1995, 1996). The present study reveals that 5-HT reduces the amplitude of these two $\mathrm{K}^{+}$currents in MGCPNs also and shows directly that 5-HT alters the responses of these same neurons to olfactory stimuli.

It is well established that changes in current amplitude observed at a macroscopic level can be caused by modulation of the maximal conductance and/or voltage dependence of participating ion channels (see, e.g., Hille, 1992). Detailed analysis of $I_{\mathrm{A}}$ revealed that in Manduca MGC-PNs, 5-HT reduces the maximum conductance and shifts the voltage inactivation curve to more negative potentials. The window of overlap between the steadystate activation and inactivation curves is decreased during 5-HT application, and in the range of the resting potential of the MGC-PNs, tonic $I_{A}$ is primarily reduced (Fig. $5 E$ ). These changes go in the right direction to explain the depolarization, action potential broadening, and increases in excitability caused by 5 -HT and are supported by the finding that the $I_{A}$ blocker 4-AP depolarizes AL neurons (Kloppenburg, unpublished observation). Although it is unusual to think of $I_{A}$ as contributing to the tonic currents that set the resting potential, the results of this study indicate that tonic $I_{A}$ could indeed play a role in setting the resting 
potential in Manduca MGC-PNs. Thus, 5-HT-induced reduction of $I_{A}$ may contribute, at least in part, to the tonic depolarization and increase in cell excitability observed in this study, as well as in previous studies (Kloppenburg and Hildebrand, 1995; Mercer et al., 1996).

In addition to modulating $I_{A}, 5$-HT decreased the maximal conductance of $I_{\mathrm{K}(\mathrm{V})}$. In contrast to its effects on $I_{A}, 5$-HT had no effect on the voltage dependence for steady-state activation or inactivation of $I_{\mathrm{K}(\mathrm{V})}$. The decrease in $g_{\max }$ is consistent also with the changes in electrophysiological properties of AL neurons observed in this study. Modeling studies demonstrate that modulation of $I_{\mathrm{K}(\mathrm{V})}$ could be an effective mechanism to change neuronal resting potential and firing frequency in neurons (Golowasch et al., 1992; Harris-Warrick et al., 1995). However, the relative contributions of $I_{A}$ and $I_{\mathrm{K}(\mathrm{V})}$ to the 5-HT-induced changes in cell excitability and spike waveform in $M$. sexta have yet to be determined.

In sensory neurons of Aplysia californica, at least three distinct $\mathrm{K}^{+}$currents have been implicated in 5-HT-induced increases in spike duration and excitability: a relatively voltage-independent $\mathrm{K}^{+}$current, $I_{\mathrm{K}(S)}$ (Klein and Kandel, 1980; Klein et al., 1982); a voltage-dependent current similar to the delayed rectifier $I_{\mathrm{K}(\mathrm{V})}$ (Baxter and Byrne, 1989, 1990); and a Ca ${ }^{2+}$-activated $\mathrm{K}^{+}$current, $I_{\mathrm{K}(\mathrm{Ca})}$ (Walsh and Byrne, 1989). Increased excitability is thought to result from reduction of $I_{\mathrm{K}(S)}$ (Byrne et al., 1990), whereas all three of these $\mathrm{K}^{+}$currents contribute to the broadening of spikes (Klein et al., 1982; Siegelbaum et al., 1982; Baxter and Byrne, 1990; Byrne et al., 1990; Byrne and Kandel, 1996). In Aplysia, 5-HT has been strongly implicated in associative learning and memory, both at the cellular and at the behavioral level (e.g., Kandel and Schwartz, 1982; Carew and Sahley, 1986; Byrne et al., 1993; Hawkins et al., 1993; Byrne and Kandel, 1996; Carew, 1996). Examination of the associative-learning capabilities of moths has revealed that moths, like honey bees (Menzel, 1990, 1993; Mauelshagen and Greggers, 1993; Hammer and Menzel, 1995; Menzel and Müller, 1996), exhibit strong learning of behaviorally relevant olfactory cues (Hartlieb, 1996; Fan et al., 1997) (K. Daly and B. Smith, personal communication). Because increasing evidence suggests that the antennal lobes play a role in the formation of such memories (Menzel and Müller, 1996; Sigg et al., 1997), it is tempting to speculate that 5-HT modulation of antennal-lobe neurons may be involved not only in the short-term facilitation of olfactory responses but also in long-term changes that affect the functional and structural plasticity of the antennal lobes of the brain.

The functional significance of the modulatory effects of 5-HT on olfactory information processing in the ALs and for olfactiondependent behavior has yet to be fully elucidated. However, Linn and Roelofs (1986) reported that in the moth Trichoplusia ni, exogenously applied 5-HT can extend the time window during which pheromone-induced behavior can be elicited and random motor activity can be expressed, and in the moth Lymantria dispar, 5-HT enhances circadian rhythm-dependent general motor activity (Linn et al., 1992). Interestingly, in the ALs of $M$. sexta, 5-HT levels were lowest in the middle of the subjective day, which is a time when these moths are inactive (Lingren et al., 1977). Surges in 5-HT levels around subjective dusk, and to a lesser extent also at subjective dawn, correlate well with reported increases in the levels of behavioral activity at these times. At night, especially around dawn and dusk, $M$. sexta are involved in mating and searching for host plants (Gilmore, 1938; Lingren et al., 1977), both of which involve goal-directed flight that is guided by olfactory cues (Arbas et al., 1993). The effects of 5-HT on Manduca AL neurons that have been described here and in previous studies (Kloppenburg and Hildebrand, 1995; Mercer et al., 1996) suggest that 5-HT released in the ALs at these times would increase the moth's responsiveness to olfactory stimuli.

5-HT has been implicated in adjusting the sensitivity of sensory systems in many species (e.g., see introductory remarks), and the modifications involved often exhibit a circadian rhythm that reflects changing environmental conditions as well as the behavioral demands of the animal. One example is 5-HT modulation of insect photoreceptors (Weckström and Laughlin, 1995). Voltagesensitive $\mathrm{K}^{+}$currents tune the photoreceptor membrane to match the gain and response dynamics of the phototransduction cascade (Weckström et al., 1991), and these conductances can be up- and downregulated to adapt the receptor to changes in light intensity. In the locust, the current profile of the photoreceptors switches diurnally between a day state and a night state, characterized by noninactivating and inactivating $\mathrm{K}^{+}$currents, respectively, and this change can be induced by 5-HT (Cuttle et al., 1995). In Drosophila photoreceptors, exogenously applied 5-HT alters the voltage dependence of a transient and a sustained $\mathrm{K}^{+}$current to more positive membrane potentials (Hevers and Hardie, 1995).

Our results suggest that in the olfactory system of $M$. sexta, 5-HT is involved in regulating the sensitivity of AL neurons, at least in part, via the modulation of $\mathrm{K}^{+}$channel activity in these cells. The modulatory effects of 5-HT in the AL of the moth seem likely to have a significant impact on $M$. sexta's performance of odor-dependent behaviors.

\section{REFERENCES}

Arbas EA, Willis MA, Kanzaki R (1993) Organization of goal-oriented locomotion: pheromone-modulated flight behavior of moths. In: Biological neural networks in invertebrate neuroethology and robotics (Beer RD, Ritzmann RE, McKenna T, eds), pp 159-198. Boston: Academic.

Armstrong CM, Bezanilla F (1974) Charge movement associated with the opening and closing of the activation gates of the $\mathrm{Na}$ channels. J Gen Physiol 63:533-552.

Baxter DA, Byrne JH (1989) Serotonergic modulation of two potassium currents in the pleural sensory neurons of Aplysia. J Neurophysiol 62:665-679.

Baxter DA, Byrne JH (1990) Differential effects of cAMP and serotonin on membrane currents in the pleural sensory cells of Aplysia. J Neurophysiol 64:978-990.

Bell RA, Joachim FA (1976) Techniques for rearing laboratory colonies of tobacco hornworms and pink bollworms. Ann Entomol Soc Am 69:365-373.

Byrne JH, Kandel ER (1996) Presynaptic facilitation revisited: state and time dependence. J Neurosci 16:425-435.

Byrne JH, Cleary LJ, Baxter DA (1990) Aspects of the neural and molecular mechanisms of short-term sensitization in Aplysia: modulatory effects of serotonin and cAMP on duration of action potentials, excitability and membrane currents in tail sensory neurons. In: The biology of memory (Squire LR, Lindenlaub E, eds), pp 7-28. New York: Springer.

Byrne JH, Zwartjes R, Homayouni R, Critz S, Eskin A (1993) Roles of second messenger pathways in neuronal plasticity and in learning and memory: insights gained from Aplysia. In: Advances in second messenger and phosphoprotein research (Nairn AC, Shenolikar S, eds), pp 47-108. New York: Raven.

Carew TJ (1996) Molecular enhancement of memory function. Neuron 16:5-8.

Carew TJ, Sahley CJ (1986) Invertebrate learning and memory: from behavior to molecules. Annu Rev Neurosci 9:435-487.

Christensen TA, Hildebrand JG (1987) Male-specific, sex-pheromoneselective projection neurons in the antennal lobes of the moth Manduca sexta. J Comp Physiol [A] 160:553-569.

Christensen TA, Hildebrand JG, Tumlinson JH, Doolittle RE (1989) Sex pheromone blend of Manduca sexta: responses of central olfactory 
interneurons to antennal stimulation in male moth. Arch Insect Biochem Physiol 10:281-291.

Christensen TA, Heinbockel T, Hildebrand JG (1996) Olfactory information processing in the brain: encoding chemical and temporal features of odors. J Neurobiol 30:82-91.

Cuttle MF, Hevers W, Laughlin SB, Hardie RC (1995) Diurnal modulation of photoreceptor potassium conductance in the locust. J Comp Physiol [A] 176:307-316.

Edwards FA, Konnerth A, Sakmann B, Takahashi T (1989) A thin slice preparation for patch clamp recordings from neurones of the mammalian central nervous system. Pflügers Arch 414:600-612.

Ewald DA, Roper SD (1994) Bidirectional synaptic transmission in Necturus taste buds. J Neurosci 14:3791-3804.

Fan R-J, Anderson P, Hanson BS (1997) Behavioural analysis of olfactory conditioning in the moth Spodoptera littoralis (Boidsd.) (Lepidoptera: Noctuidae). J Exp Biol 200:2969-2976.

Gilmore JU (1938) Observations on the hornworms attacking tobacco in Tennessee and Kentucky. J Econ Entomol 31:706-712.

Golowasch J, Buchholtz F, Epstein IR, Marder E (1992) The contribution of individual ionic currents to activity of a model stomatogastric ganglion neuron. J Neurophysiol 67:341-349.

Hamill OP, Marty A, Neher E, Sakmann B, Sigworth RF (1981) Improved patch-clamp techniques for high-resolution current recording from cell-free membrane patches. Pflügers Arch 391:85-100.

Hammer M, Menzel R (1995) Learning and memory in the honeybee. J Neurosci 15:1617-1630.

Hansson BS, Christensen TA, Hildebrand JG (1991) Functionally distinct subdivisions of the macroglomerular complex in the antennal lobe of the male sphinx moth Manduca sexta. J Comp Neurol 312:264-278.

Harris-Warrick RM, Coniglio LM, Barazangi N, Guckenheimer J, Gueron S (1995) Dopamine modulation of transient potassium current evokes phase shifts in a central pattern generator network. J Neurosci 15:342-358.

Hartlieb E (1996) Olfactory conditioning in the moth Heliothis virescens. Naturwissenschaften 83:87-88.

Häusser M, Clark BA (1997) Tonic synaptic inhibition modulates neuronal output pattern and spatiotemporal synaptic integration. Neuron 19:665-678.

Hawkins RD, Kandel ER, Siegelbaum SA (1993) Learning to modulate transmitter release: themes and variations in synaptic plasticity. Annu Rev Neurosci 16:625-665.

Heinbockel T, Kloppenburg P, Hildebrand JG (1998) Pheromoneevoked potentials and oscillations in the antennal lobes of the sphinx moth Manduca sexta. J Comp Physiol [A] 182:703-714.

Hevers W, Hardie RC (1995) Serotonin modulates the voltage dependence of delayed rectifier and shaker potassium channels in Drosophila photoreceptors. Neuron 14:845-856.

Hildebrand JG (1995) Analysis of chemical signals by nervous systems. Proc Natl Acad Sci USA 92:67-74.

Hildebrand JG (1996) Olfactory control of behavior in moths: central processing of odor information and the functional significance of olfactory glomeruli. J Comp Physiol [A] 178:5-19.

Hildebrand JG, Shepherd GM (1997) Mechanisms of olfactory discrimination: converging evidence for common principles across phyla. Annu Rev Neurosci 20:595-631.

Hille B (1992) Ionic channels of excitable membranes. Sunderland, MA: Sinauer.

Hodgkin AL, Huxley AF (1952) A quantitative description of membrane current and its application to conduction and excitation in nerve. J Physiol (Lond) 117:500-544.

Homberg U, Hildebrand JG (1989) Serotonin-immunoreactive neurons in the median protocerebrum and suboesophageal ganglion in the sphinx moth Manduca sexta. Cell Tissue Res 258:1-24.

Homberg U, Montague RA, Hildebrand JG (1988) Anatomy of antenno-cerebral pathways in the brain of the sphinx moth Manduca sexta. Cell Tissue Res 254:255-281.

Homberg U, Christensen TA, Hildebrand JG (1989) Structure and function of the deutocerebrum in insects. Annu Rev Entomol 34:477-501.

Kandel ER, Schwartz JH (1982) Molecular biology and learning: modulation of transmitter release. Science 218:433-443.

Kent KS, Hoskins SG, Hildebrand JG (1987) A novel serotoninimmunoreactive neuron in the antennal lobe of the sphinx moth Manduca sexta persists throughout postembryonic life. J Neurobiol 18:451-465.

Klein M, Kandel ER (1980) Mechanism of calcium current modulation underlying presynaptic facilitation and behavioral sensitization in Aplysia. Proc Natl Acad Sci USA 77:6912-6916.
Klein M, Camardo J, Kandel ER (1982) Serotonin modulates a specific potassium current in the sensory neurons that show presynaptic facilitation in Aplysia. Proc Natl Acad Sci USA 79:5713-5717.

Kloppenburg P, Hildebrand JG (1995) Neuromodulation by 5-hydroxytryptamine in the antennal lobe of the sphinx moth Manduca sexta. J Exp Biol 198:603-611.

Kloppenburg P, Kirchhof BS, Mercer AR (1999) Voltage-activated currents from adult honeybee (Apis mellifera) antennal motor neurons recorded in vitro and in situ. J Neurophysiol 81:39-48.

Lingren PD, Greene GL, Davis DR, Baumhover AH, Henneberry TJ (1977) Nocturnal behavior of four Lepitopteran pests that attack tobacco and other crops. Ann Entomol Soc Am 70:161-167.

Linn CE, Roelofs WL (1986) Modulatory effects of octopamine and serotonin on male sensitivity and periodicity of response to sex pheromone in the cabbage looper moth, Trichoplusia ni. Arch Insect Biochem Physiol 3:161-171.

Linn CE, Campell MG, Roelofs WL (1992) Photoperiod cues and modulatory action of octopamine and 5-hydroxytryptamine on locomotor and pheromone response in male gypsy moth, Lymantria dispar. Arch Insect Biochem Physiol 20:265-284.

Lowry OH, Rosebrough NJ, Farr AL, Randall RJ (1951) Protein measurement with the Folin phenol reagent. J Biol Chem 193:265-275.

Mauelshagen J, Greggers U (1993) Experimental access to associative learning in honeybees. Apidiologie 24:249-266.

Menzel R (1990) Learning, memory and "cognition" in honey bees. In: Neurobiology of comparative cognition (Kesner RP, Olden DS, eds), pp 237-292. Hillsdale, NJ: Erlbaum.

Menzel R (1993) Associative learning in honey bees. Apidiologie 24:157-168

Menzel R, Müller U (1996) Learning and memory in honeybees: from behavior to neural substrates. Annu Rev Neurosci 19:379-404.

Mercer AR, Hayashi JH, Hildebrand JG (1995) Modulatory effects of serotonin on voltage-activated currents in cultured antennal lobe neurons of the sphinx moth Manduca sexta. J Exp Biol 198:613-627.

Mercer AR, Kloppenburg P, Hildebrand JG (1996) Serotonin-induced changes in the excitability of cultured antennal-lobe neurons of the sphinx moth Manduca sexta. J Comp Physiol [A] 178:21-31.

Olsen OH, Calabrese RL (1996) Activation of intrinsic and synaptic currents in leech heart interneurons by realistic waveforms. J Neurosci 16:4958-4970.

Peterson GL (1977) A simplification of the protein assay method of Lowry et al. which is more generally applicable. Anal Biochem 83:346-356.

Pichon Y, Sattelle DB, Lane NJ (1972) Conduction processes in the nerve cord of the moth Manduca sexta in relation to its ultrastructure and haemolymph ionic composition. J Exp Biol 56:717-734.

Sakmann B, Edwards F, Konnerth A, Takahashi T (1989) Patch clamp techniques used for studying synaptic transmission in slices of mammalian brain. Q J Exp Physiol 74:1107-1118.

Salkoff L, Baker K, Butler A, Cuvarrubias M, Pak MD, Wei A (1992) An essential "set" of $\mathrm{K}^{+}$channels conserved in flies, mice and humans. Trends Neurosci 15:161-166.

Siegelbaum SA, Camardo JS, Kandel ER (1982) Serotonin and cyclic AMP close single $\mathrm{K}^{+}$channels in Aplysia sensory neurons. Nature 299:413-417.

Sigg D, Thompson CM, Mercer AR (1997) Activity-dependent changes to the brain and behavior of the honey bee Apis mellifera. J Neurosci 17:7148-7156.

Sun XJ, Tolbert LP, Hildebrand JG (1993) Ramification pattern and ultrastructural characteristic of the serotonin immunoreactive neuron in the antennal lobe of the moth Manduca sexta: a laser scanning confocal and electron microscopic study. J Comp Neurol 338:5-16.

Wachowiak M, Ache BW (1994) Morphology and physiology of multiglomerular olfactory projection neurons in the spiny lobster. J Comp Physiol [A] 175:35-48.

Wachowiak M, Diebel CE, Ache BW (1996) Functional organization of olfactory processing in the accessory lobe of the spiny lobster. J Comp Physiol [A] 178:211-226.

Walsh JP, Byrne JH (1989) Modulation of a steady-state $\mathrm{Ca}^{2+}$-activated $\mathrm{K}^{+}$current in tail sensory neurons of Aplysia: role of serotonin and cAMP. J Neurophysiol 61:32-44.

Weckström M, Laughlin SB (1995) Visual ecology and voltage-gated ion channels in insect photoreceptors. Trends Neurosci 18:17-21.

Weckström M, Hardie RC, Laughlin SB (1991) Voltage-activated potassium channels in blowfly photoreceptors and their role in light adaptation. J Physiol (Lond) 440:635-657. 